\title{
Multi-Scale Structural Studies of Sequential Ionic Liquids and Alkali Pretreated Corn Stover and Sugarcane Bagasse
}

\author{
Ishwinder Kaur ${ }^{1,2}$, Girish Sahni ${ }^{*}$ \\ ${ }^{1}$ CSIR-Institute of Microbial Technology, Chandigarh, India \\ ${ }^{2}$ Panjab University, Chandigarh, India \\ Email: ishwinder30@gmail.com, ^girishsahni@gmail.com
}

How to cite this paper: Kaur, I. and Sahni, G. (2018) Multi-Scale Structural Studies of Sequential Ionic Liquids and Alkali Pretreated Corn Stover and Sugarcane Bagasse. Green and Sustainable Chemistry, 8, 92114. https://doi.org/10.4236/gsc.2018.81007

Received: November 2, 2017

Accepted: February 8, 2018

Published: February 11, 2018

Copyright $\odot 2018$ by authors and Scientific Research Publishing Inc. This work is licensed under the Creative Commons Attribution International License (CC BY 4.0).

http://creativecommons.org/licenses/by/4.0/

\begin{abstract}
The complexity of plant cell walls impedes the conversion of cellulosic biomass to sugars. Pretreatment becomes a necessity to increase the digestibility of biomass. An in-depth understanding of the structure and underlying mechanisms governing deconstruction process is important. In the present study, the comprehensive investigation of morphological and structural changes in corn stover and sugarcane bagasse following ionic liquids dissolution and alkaline extraction was done using Fourier transform infrared spectroscopy, Thermogravimetric analysis, Confocal scanning laser microscopy, Atomic force microscopy and Dynamic light scattering studies. Both the substrates were pretreated with ILs 1-ethyl-3-methylimidazolium acetate and 1-butyl3-methylimidazolium acetate followed by alkaline extraction. The pronounced changes such as lignin, hemicelluloses removal and decreased cellulose crystallinity after the pretreatments lead to the structural transformation of matrix polymers. The enzymatic hydrolysis showed 90\% theoretical sugar yield in case of sugarcane bagasse and $80 \%$ in corn stover following synergistically combined pretreatments.
\end{abstract}

\section{Keywords}

Pretreatment, Ionic Liquids, Alkali, Structural Studies, Hydrolysis

\section{Introduction}

Lignocellulosic biomass is the most abundant, renewable and sustainable resource on the earth to be used as a greener and clean energy alternative. Biomass 
in the form of agricultural and forest residues, industrial and municipal wastes, and few of the energy crops is a huge productive source for the production of bio-ethanol [1] which is considered as a promising resource for overcoming the problem of depleting fossil fuel reserves. The recalcitrant nature of biomass is a barrier in the production of fermentable sugars. Henceforth, pretreatment is an essential step in disrupting the various cell wall components to further enhance the accessibility of the biomass to enzymes [2]. Different pretreatment techniques are employed resulting in the decreased crystallinity of cellulose alongwith effective removal of hemicelluloses as well as lignin from the matrix polymers [3] [4]. Currently, ionic liquids (ILs) are being used as green solvents for the effective pretreatment of different biomasses and are exceptionally superior in the cellulose dissolution [5]. Li et al. [6] optimized and elegantly validated the use of combined ionic liquid/s and alkali for the pretreatment of Eucalyptus. Moreover, it has been shown in the previous studies that acetate ILs demonstrated much better performance in delignification and swelling of biomass as compared to the chloride ILs [7] [8]. In this work, we have used the ILs having two different [EmIm] and [BmIm] cations and the same acetate anion. Although the lignin content is decreased by using ILs, yet for increasing the saccharification kinetics of model substrates, further treatment is required in combination for the maximal removal of lignin and hemicelluloses as well [6]. The alkaline pretreatment is the widely used chemical technology [9] [10] and employs different alkaline reagents. Sodium hydroxide $(\mathrm{NaOH})$ has proven to be the most effective in degradation as compared to the other alkalis used [11]. The technique reduces the degree of polymerization by cleavage of hydrolysable lignin linkages and the glycosidic bonds of the polysaccharides [12]. Henceforth, for disrupting the rigid biomass structures, alkaline pretreatment can be effectively combined with ionic liquids to synergistically enhance the hydrolytic efficiencies and the simultaneous recovery of monomeric soluble sugars. Economically, the critical steps include the selection and efficient utilization of raw substrates [13]. Corn stover and sugarcane bagasse are the promising feedstocks owing to their abundant production and easy availability round the year. Also, the agricultural residues such as corn stover, sugarcane bagasse and wheat straw are the widely used raw materials for biorefinery [14] [15]. The physical and chemical changes dictate the very evidence of extraction of lignin, partial removal of hemicelluloses and complete dissolution of cellulose owing to the effects of various pretreatments in different feedstocks varying in composition. The major key in the prediction of enzyme hydrolysis of plant cell walls to ultimately produce monomeric sugars lies in the understanding of fundamental structure of plant tissues [16]. Therefore, in depth investigation is required at ultra fine scale for comparing effects of combined pretreatments on two of the most abundant and widely used agricultural residues.

Although morphological and structural studies have been done before on the corn stover as well as sugarcane bagasse following varied pretreatments. Yet, the 
physico-chemical data for deeply understanding the action mechanism of ionic liquids working synergistically with $\mathrm{NaOH}$ is still lacking and the new combinatorial bench scale pretreatments applied in this study will unfold the response of more of the nano-scale changes for better understanding the phenomena of cell wall disruption in the two substrates of same family of grasses (monocots) deciphering the underlying physico-chemical differences after undergoing same kinds of pretreatments and subsequent hydrolysis with commercial cellulase enzyme.

In this work, the native and pretreated Corn Stover (CS) and Sugarcane Bagasse (SB) were studied comprehensively for the morphological and structural changes by using Atomic Force Microscopy (AFM), Confocal Scanning Laser Microscopy (CSLM), Fourier Transform Infrared Spectroscopy (FTIR). The thermal behavior was observed using Thermogravimetric Analysis (TGA) and the average particle size distributions after the sequential ionic liquids and alkali pretreatments was verified by Dynamic Light Scattering (DLS). Further validation of the two pretreatments in disrupting the structural integrity of CS and SB was done by enzyme hydrolysis experiment.

\section{Materials and Methods}

\subsection{Sample Preparation, Chemicals and Reagents}

Raw sugarcane bagasse was collected from a sugar mill and corn stover was collected from the fields (Punjab, India). Both the residues were finely grounded (5 - $20 \mathrm{~mm}$ ) and washed extensively with water, then dried at $60^{\circ} \mathrm{C}$ in a convection oven for a minimum of 24 hours. The composition of CS and SB has been given in the Supplementary file 1: Table S2. The ionic liquids (ILs) 1-ethyl-3-methylimidazolium acetate [EmIm][OAc] and 1-butyl-3-methylimidazolium acetate $[\mathrm{BmIm}][\mathrm{OAc}]$ used for pretreatment purposes were purchased from Sigma-Aldrich (USA) and sodium hydroxide was purchased from Thermo Fisher Scientific (USA). Cellulase from Trichoderma reesei (ATCC 26921) was procured from Sigma-Aldrich (USA). All the chemicals used were of analytical grade.

\subsection{Agro-Residues Pretreatment}

The dried residual materials were pretreated with two ionic liquids 1-ethyl-3methylimidazolium acetate [EmIm][OAc] and 1-butyl-3-methylimidazolium acetate $[\mathrm{BmIm}][\mathrm{OAc}]$ at $90^{\circ} \mathrm{C}$ for 24 hours. The biomass to ionic liquids ratio was maintained at 1:10. The pretreated biomasses were recovered using deionized water as an anti solvent which was added slowly into the ionic liquids mixtures' being continuously stirred at room temperature for 30 minutes. The regenerated biomasses obtained after filtration were washed repeatedly with deionized water till the wash solution turned colourless from dark brown colour. The recovered solids were dried in an oven at $60^{\circ} \mathrm{C}$ for 24 hours and were weighed for the recovery of solids obtained after the pretreatment. 
The ionic liquids' pretreated materials were further successively alkali fractionated at $121^{\circ} \mathrm{C}$ for 30 minutes using $2 \% \mathrm{NaOH}$ at ratio of $1: 20$ (biomass:alkali). After the pretreatment, the materials were washed thoroughly with water until the $\mathrm{pH}$ was near neutral and dried in an oven at $60^{\circ} \mathrm{C}$ for 24 hours. The pretreatments were carried out in duplicates and the results are reported as the average. The IL pretreated corn stover and sugarcane bagasse samples were labelled as CS-EtIm [Ac], CS-BmIm [Ac] and SB-EtIm [Ac], SB-BmIm [Ac] respectively. The combined IL and alkali treated samples were labeled as CS-EtIm $[\mathrm{Ac}]+\mathrm{Na}, \mathrm{CS}-\mathrm{BmIm}[\mathrm{Ac}]+\mathrm{Na}, \mathrm{SB}-\mathrm{EtIm}[\mathrm{Ac}]+\mathrm{Na}$ and SB-BmIm $[\mathrm{Ac}]+\mathrm{Na}$. The native samples were pretreated by $2 \% \mathrm{NaOH}$ also and labeled as CS-Na and SB-Na.

\subsection{Chemical Composition}

Chemical composition of corn stover and sugarcane bagasse was analyzed by gravimetric method. Hemicellulose and cellulose content was estimated using protocol by [17] [18]. Lignin composition was determined using NREL standard protocol.

\subsection{Enzymatic Hydrolysis}

The enzyme hydrolysis was performed on the combined ionic liquids and alkali pretreated substrates $(2 \% \mathrm{w} / \mathrm{v})$ using cellulase from Trichoderma reesei (15 $\mathrm{FPU} / \mathrm{g}$ ). The reaction was conducted at $50^{\circ} \mathrm{C}$ in INNOVA 44 incubator shaker (New Brunswick Scientific, USA) at $150 \mathrm{rpm}$ for 72 hours in $50 \mathrm{mM} \mathrm{Na}$ acetate buffer $\mathrm{pH} 5.0$ supplemented with $100 \mu \mathrm{g} / \mathrm{ml}$ tetracycline. The samples were taken at regular intervals and the reactions were terminated by boiling the samples for 10 minutes followed by centrifugation at $10,000 \mathrm{rpm}$. The supernatants were collected and used for total reducing sugar analysis using DNS method [19]. The experiments were performed in triplicates and the results are represented as average mean values.

\subsection{Analytical Methods}

\subsubsection{Atomic Force Microscopy (AFM)}

AFM analysis of the substrates was performed as described earlier by [20]. All the AFM measurements were made with Veeco Innova System, USA. The images were acquired in tapping mode using silicon tips with aluminium coating at a resonance frequency of $300 \mathrm{kHz}$ and spring constant of $40 \mathrm{~N} / \mathrm{m}$. The images were processed using Gwyddion software.

\subsubsection{Confocal Scanning Laser Microscopy (CSLM)}

The thin sections of native and pretreated samples were positioned on microscopic glass slides with cover slips. The images were obtained at $10 \times$ objective using Nikon A1R (Japan) at two laser wavelengths (405 nm and $488 \mathrm{~nm}$ ).

\subsubsection{Scanning Electron Microscopy (SEM)}

The surface morphology of the untreated and pretreated substrates' was ob- 
served using scanning electron microscopy at a voltage of $20 \mathrm{kV}$. The sample was sputter coated for 120 seconds using $12-15 \mathrm{~mA}$ of current and the digital images, thereafter, were obtained using magnifications ranging from $200 \times$ to 18,000× using Carl Zeiss (AG-EVO ${ }^{\circledR} 40$ Series) instrument.

\subsubsection{Fourier Transform Infrared Spectroscopy (FTIR)}

The FTIR analysis of the native and pretreated samples was performed to detect the changes in respective functional groups. The pellets were prepared by mixing $1 \mathrm{mg}$ of sample with $100 \mathrm{mg}$ of spectroscopic grade $\mathrm{KBr}$ in a pestle mortar. The samples were then subjected to pressures of 10 tons in a Perkin Elmer hydraulic press. The spectra were recorded in a Vertex 70 spectrophotometer (Bruker OPTIK, GmbH) in the frequency range of $4000 \mathrm{~cm}^{-1}-400 \mathrm{~cm}^{-1}$ at $4 \mathrm{~cm}^{-1}$ resolution with 32 scans per sample. Lynam and Coronella [21] gave the concept of pretreatment index (Ip) which is the ratio of the intensities of the FTIR peaks at $896 \mathrm{~cm}^{-1}$ (amorphous cellulose) and $1515 \mathrm{~cm}^{-1}$ (lignin) divided by the same ratio for the raw biomass. The estimation of respective pretreatment's effectiveness is provided by the same [22]. Total Crystallinity Index (TCI) refers to the absorbance ratios of peaks at 1368 and $2903 \mathrm{~cm}^{-1}$ and indicate the percentage of cellulose crystallinity in the respective substrates' structures [23]. High value will have a higher TCI and reduction in values indicate the decrease in crystallinity.

\subsubsection{Thermogravimetric Analysis (TGA)}

It was conducted using a TGA/DSC1 system (Mettler-Toledo, Inc., USA). A 5 mg sample which was weighed into $70 \mu \mathrm{l}$ of alumina crucible was heated from $25^{\circ} \mathrm{C}$ to $1000^{\circ} \mathrm{C}$ at the rate of $10^{\circ} \mathrm{C} / \mathrm{min}$ and analyzed in the presence of inert environment (nitrogen gas).

\subsubsection{Dynamic Light Scattering (DLS)}

The particle size distribution for all the native and pretreated substrates was determined using Malvern (UK) Zetasizer Nano series instrument with laser at a wavelength of $633 \mathrm{~nm}$ and at a constant temperature of $25^{\circ} \mathrm{C} .1 \% \mathrm{w} / \mathrm{w}$ samples were dispersed in deionized water by sonication. The uppermost $1 \mathrm{ml}$ sample dispersion was taken and diluted 100 times for further DLS measurements.

\section{Results and Discussion}

The varied structural, chemical changes after the application of sequential treatments on the two agro-residues were observed with the help of different techniques and quantitative evaluation of the post treatments' effects was supported through the extent of hydrolysis.

\subsection{FTIR Spectra Analysis}

The FTIR spectra were obtained to determine the functional groups and the chemical changes in the structures of native and pretreated corn stover and su- 
garcane bagasse samples as shown in Figure 1(a), Figure 1(b). Distinct spectral features were observed in native as well as pretreated substrates. The data obtained in the frequency range of $3800-3000 \mathrm{~cm}^{-1}$ clearly showed that the native, IL treated, alkali fractionated and IL $+\mathrm{NaOH}$ sequentially treated $\mathrm{CS}$ and SB materials comprised bands providing evidence of crystalline structure of cellulose [24]. The two peaks of $\mathrm{CH} 2$ symmetric and $\mathrm{CH}$ asymmetric stretching respectively were present at $2850 \mathrm{~cm}^{-1}$ and $2918 \mathrm{~cm}^{-1}$ being characteristic of cellulose [25]. The slight disturbances in the CS-EtIm [Ac]+Na and CS-BmIm [Ac]+Na peak at $2850 \mathrm{~cm}^{-1}$ indicated that after these pretreatments, the cellulose chain had been affected [26]. In short, the presence of lignocellulosic matrix was confirmed by these bands. Functional assignment of the respective absorbance bands has been mentioned in the Supplementary file 1: Table S1. It was critically observed that after $\mathrm{IL}+\mathrm{NaOH}$ pretreatments in $\mathrm{CS}$ as well as SB, the peak at 1732 $\mathrm{cm}^{-1}$ band almost disappeared as compared to the IL pretreated ones [6] [27]. This effect confirmed the cleavage of the ester bands specifically acetyl

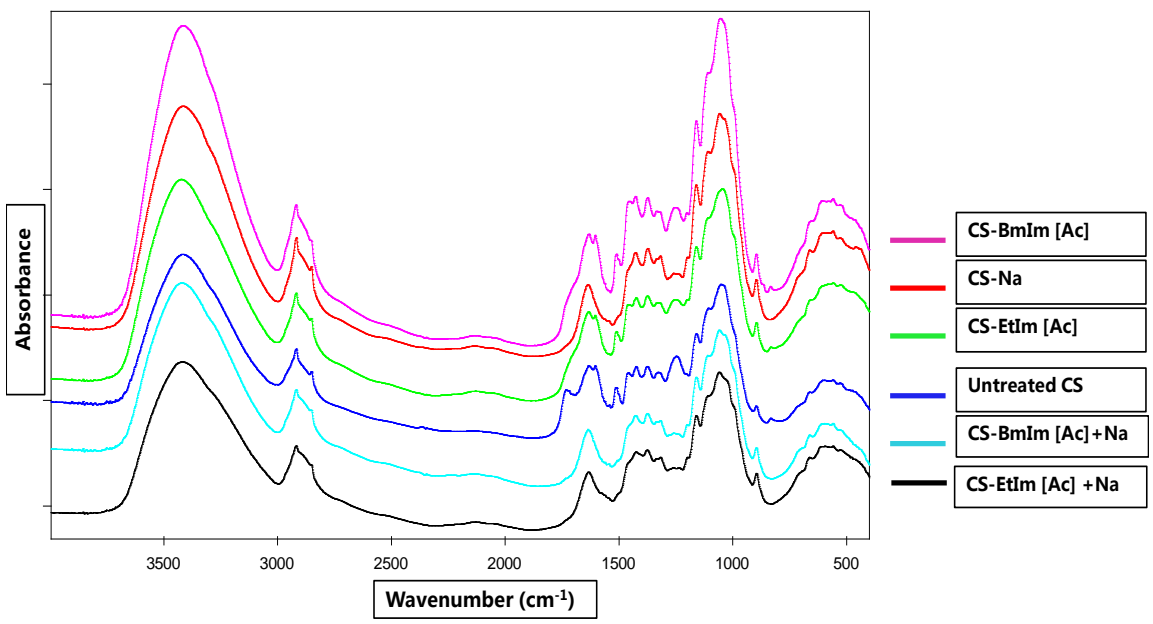

(a)

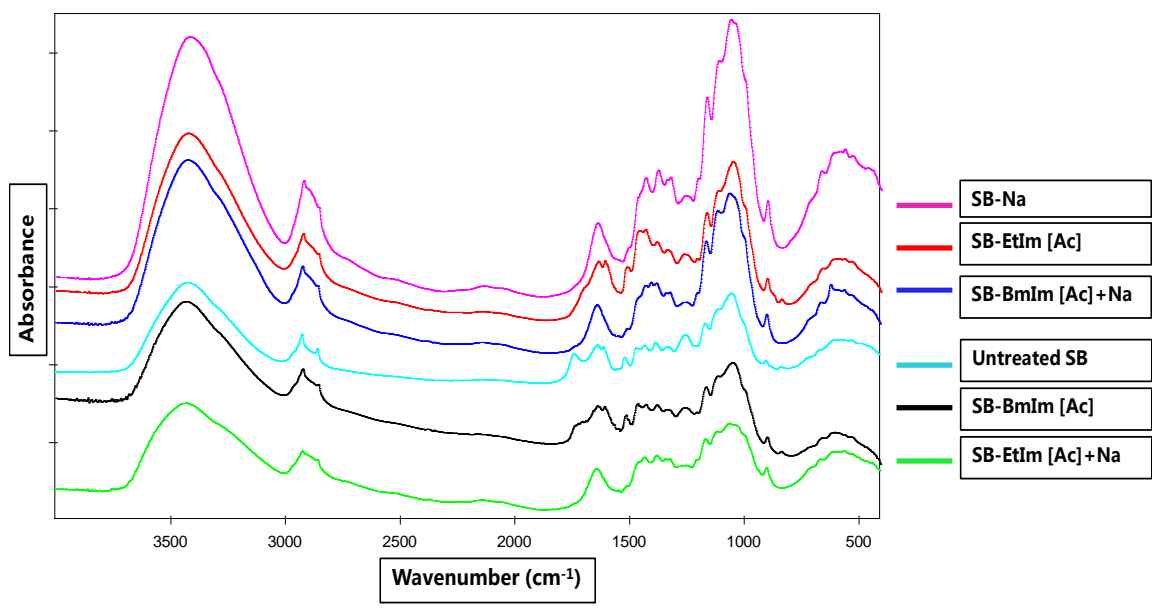

(b)

Figure 1. FTIR spectra of (a) untreated, IL, $\mathrm{NaOH}$ and IL $+\mathrm{NaOH}$ treated Corn Stover (b) untreated, IL, $\mathrm{NaOH}$ and IL+NaOH treated Sugarcane Bagasse. 
groups in hemicelluloses which are considered as barriers for lignocellulosic degradation [2] [28] [29]. The extensive deacetylation might have further contributed to enhanced enzyme digestibility [30]. There was a sharp increase in intensity in $\mathrm{SB}$ at $1638 \mathrm{~cm}^{-1}$ peak corresponding to $\mathrm{C}=\mathrm{C}$ aromatic skeletal vibrations which denoted the partial lignin removal. The same effect could be observed in case of IL and $\mathrm{IL}+\mathrm{NaOH}$ pretreated $\mathrm{CS}$ as compared to the untreated CS spectra. The another lignin aromatic skeletal vibrational peak at $1505 \mathrm{~cm}^{-1}$ decreased after pretreatment with $\mathrm{NaOH}$ and $\mathrm{IL}+\mathrm{NaOH}$ pretreated $\mathrm{SB}$ again indicating the delignification of biomass. The CS-BmIm [Ac] and SB-EtIm [Ac] materials showed an increase in peak intensity which could be due to the removal of amorphous cellulose resulting in increased lignin content [6] [22] [31]. The changes around these peaks were evident of effective lignin degradation after the combined $\mathrm{IL}+\mathrm{NaOH}$ pretreatments. Here, we could observe the different responses of CS and SB to $[\mathrm{EmIm}][\mathrm{OAc}]$ and $[\mathrm{BmIm}][\mathrm{OAc}]$. The band around $1427 \mathrm{~cm}^{-1}$ (strong in type I crystalline) had slightly increased intensity in case of $\mathrm{IL}+\mathrm{NaOH}$ pretreated $\mathrm{CS}$ and $\mathrm{SB}$ substrates possibly indicating the removal of amorphous cellulose [6]. The peak at $1373 \mathrm{~cm}^{-1}$ corresponding to C-H deformation in cellulose and hemicelluloses showed slight decrease in intensities in case of $\mathrm{IL}+\mathrm{NaOH}$ pretreated SB compared to the increase in SB-Na whereas in case of CS, no prominent change was observed at the same frequency [32]. The decreased intensities in case of SB could be related to the partial removal of hemicelluloses as well as the transformation of crystalline to amorphous form and vice versa in SB-Na. The intensity of peaks decreased around $1259 \mathrm{~cm}^{-1}$ in case of $\mathrm{NaOH}$ and IL pretreatments and disappeared completely in case of SB-EtIm $[\mathrm{Ac}]+\mathrm{Na}$ followed by SB-BmIm [Ac] $+\mathrm{Na}$ owing to the removal of hemicelluloses. In case of CS, the flattened peaks were observed in case of $\mathrm{NaOH}$ and $\mathrm{IL}+\mathrm{NaOH}$ pretreated $\mathrm{CS}$ as compared to the native one again indicating hemicelluloses removal but no changes were observed in CS-EtIm [Ac] and CS-BmIm [Ac]. In case of $\mathrm{SB}$, more of the hemicelluloses were removed and the results were in agreement with enzymatic hydrolysis. In CS, the peaks at $1450 \mathrm{~cm}^{-1}$ showed reduced intensity in case of CS-Na, CS-EtIm [Ac] $+\mathrm{Na}$ and CS-BmIm $[\mathrm{Ac}]+\mathrm{Na}$ whereas the same peaks almost disappeared at band of $1595 \mathrm{~cm}^{-1}$. At both the band positions, there were insignificant changes in case of CS-EtIm [Ac] and CS-BmIm [Ac] pretreated substrates. In case of SB also, the peaks disappeared completely in case of SB-Na, SB-EtIm $[\mathrm{Ac}]+\mathrm{Na}$ and SB-BmIm [Ac]+ $\mathrm{Na}$. The above phenomena indicated the removal of lignin altogether with showing the increase in cellulose contents relatively [33]. The band at $897 \mathrm{~cm}^{-1}$ representing the $\beta-1,4$ glycosidic linkages showed very prominent increase in intensity in case of all the pretreated CS and SB samples. Similarly, in a study by Corrales et al., steam pretreated sugarcane bagasse also showed an increased signal at $897 \mathrm{~cm}^{-1}$ resulting from the exposure of bagasse pretreated fibres [34].

In case of CS, the effect is more pronounced in case of CS-Na indicating the more amorphous cellulose contents than the untreated ones [20]. The phenomena arising from different spectral FTIR peaks in the pretreated substrates 
confirmed the pronounced changes such as lignin, hemicelluloses removal and increase of amorphous contents in cellulose with decreased cellulose crystallinity as were observed in case of sequential $\mathrm{IL}+\mathrm{NaOH}$ pretreated $\mathrm{CS}$ and SB materials.

Pretreatment Index (Ip) and Total Crystallinity Index (TCI)

Table 1 showing the Pretreatment index [Ip] and TCI values could be correlated in case of IL and $\mathrm{NaOH}$ pretreated $\mathrm{CS}$ and SB. It could be seen that the Ip value increased after the $\mathrm{IL}+\mathrm{NaOH}$ pretreatments in both $\mathrm{CS}$ and $\mathrm{SB}$, indicating the efficacy of same. Whereas, the decreased TCI values indicated the disordered structure of cellulose owing to lesser crystallinity.

\subsection{Thermogravimetric Analysis}

TG profiles represent the instantaneous weight loss percentage of the biomass samples with increasing temperature (Figure 2(a), Figure 2(b)). The TG curves of the untreated and pre-treated CS and SB samples could be roughly divided into three zones. The slight weight decline in the first region around $100^{\circ} \mathrm{C}$ was due to the dehydration of the materials and the degradation of the samples started after $250^{\circ} \mathrm{C}$. The second region is the active pyrolysis and the third represents the passive pyrolysis. According to Raveendran et al. [35], the three prominent events could be observed in a TGA graph: 1) moisture loss below $100^{\circ} \mathrm{C}$; 2) extractives decomposition between $100^{\circ} \mathrm{C}-250^{\circ} \mathrm{C}$, mainly hemicellulose decomposition between $250^{\circ} \mathrm{C}-350^{\circ} \mathrm{C}$, cellulose decomposition between $350^{\circ} \mathrm{C}-500^{\circ} \mathrm{C}$ and lignin decomposition beyond $500^{\circ} \mathrm{C}$. TGA data is shown in the form of thermogravimetry (TG) curve and its first derivative known as differential thermogravimetry (DTG) curve. The native corn stover started degrading approximately at $268^{\circ} \mathrm{C}$, and degraded almost $50 \%$ at $410^{\circ} \mathrm{C}$ [36]. Compared to the untreated sample, the IL, $\mathrm{NaOH}$ and $\mathrm{IL}+\mathrm{NaOH}$ pretreated samples began degrading at $275^{\circ} \mathrm{C}$ and the high degradation temperatures and thermal stabilities were observed for the CS-Na, CS-EtIm [Ac]+Na and CS-BmIm [Ac]+Na samples followed by CS-EtIm [Ac] and CS-BmIm [Ac]. This effect could be attributed to the partial removal of hemicelluloses and lignin [37]. This is in contrast to one of the studies where the thermal stabilities decreased for imidazolium-based ILs with increasing cellulose dissolution capability [38]. Whereas the

Table 1. Particle sizes of untreated and combined pretreated substrates prior to enzyme hydrolysis (nm), FTIR Pretreatment Index (Ip) and Total Crystallinity Index (TCI) after the combined pretreatments.

\begin{tabular}{ccccccc}
\hline Samples & $\begin{array}{c}\text { Untreated } \\
\text { CS }\end{array}$ & $\begin{array}{c}\text { Untreated } \\
\text { SB }\end{array}$ & $\begin{array}{c}\text { CS-EtIm } \\
\text { [Ac]+Na }\end{array}$ & $\begin{array}{c}\text { SB-EtIm } \\
{[\text { Ac] }+N a}\end{array}$ & $\begin{array}{c}\text { CS-BmIm } \\
\text { [Ac]+Na }\end{array}$ & $\begin{array}{c}\text { SB-BmIm } \\
\text { [Ac]+Na }\end{array}$ \\
\hline $\begin{array}{c}\text { Z-Average } \\
\text { Diameter [nm] } \\
\text { Pretreatment } \\
\text { Index [Ip] }\end{array}$ & 626.2 & 540 & 741 & 409.2 & 477.7 & 592.5 \\
$\begin{array}{c}\text { Total Crystallinity } \\
\text { Index (TCI) }\end{array}$ & 0.935 & 1.033 & 1.184 & 1.14 & 1.088 & 1.144 \\
\hline
\end{tabular}




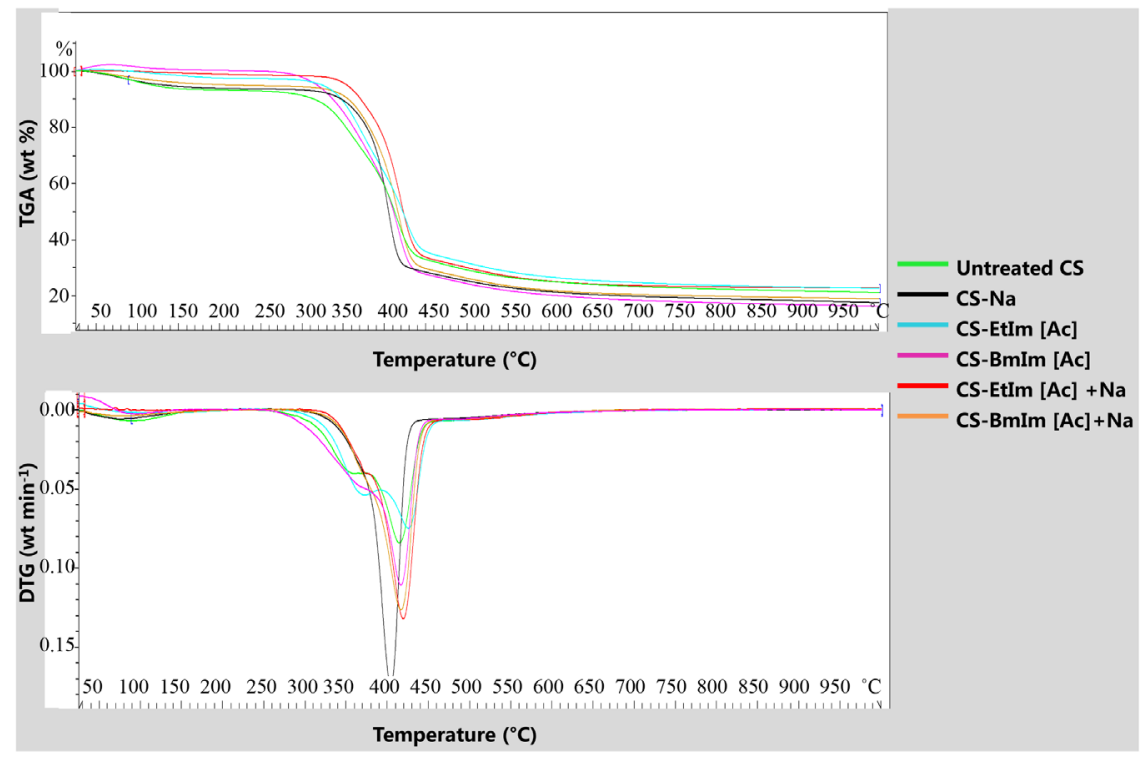

(a)

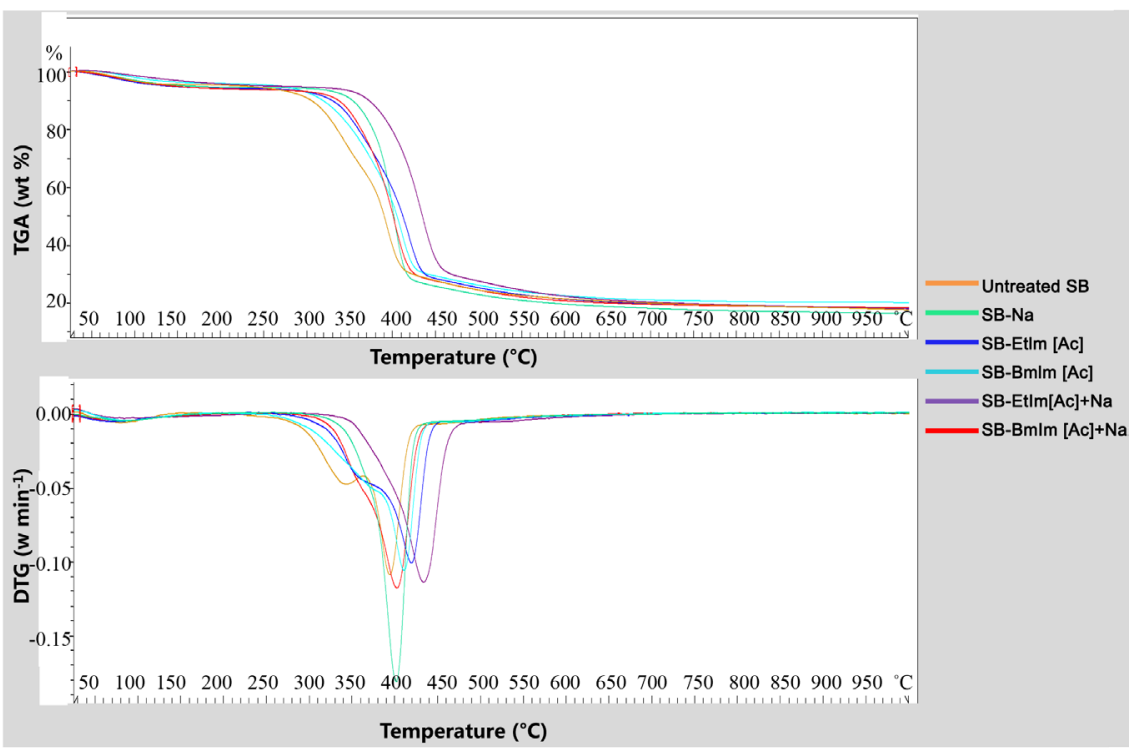

(b)

Figure 2. TGA Profiles and dTG curves (a) Untreated, IL, $\mathrm{NaOH}$ and IL+NaOH treated Corn Stover (b) Untreated, IL, $\mathrm{NaOH}$ and IL+NaOH treated Sugarcane Bagasse.

increase in thermal stability in CS-EtIm [Ac] as compared to the native CS was in accordance with the results previously reported in case of IL pretreated substrates [39]. The DTG curve of untreated CS showed two distinct peaks of first weight loss at $350^{\circ} \mathrm{C}$ in the hemicellulose region and second weight loss in the cellulose region at $415^{\circ} \mathrm{C}$ respectively showing the presence of both cellulose and hemicelluloses in the native sample [40]. In case of CS-Na and CS-BmIm [Ac]+ $\mathrm{Na}$ pre-treated, the maximum weight losses were observed at $405^{\circ} \mathrm{C}$ and $415^{\circ} \mathrm{C}$ respectively in the cellulose region and the maximum decomposition rate was observed in the case of CS-Na. The lower peak temperature of CS-Na than the native CS could be accounted due to decrease in degree of crystallization after 
the alkaline pretreatment [41]. The weight losses in the cellulose region probably indicated the absence of hemicelluloses in these pre-treated materials [40]. The single peaks in both the cases with peak values of $405^{\circ} \mathrm{C}$ and $415^{\circ} \mathrm{C}$ might also refer to the Tmax which is the temperature at which the maximum decomposition rate occurs [39]. In CS-EtIm [Ac]+Na, the first slight shoulder peak or the negligible weight loss occurred at $380^{\circ} \mathrm{C}$ in the hemicellulose zone and the second weight loss peak was observed at $418^{\circ} \mathrm{C}$ in the cellulose zone. In CSBuIm [Ac], the maximum decomposition occurs at $415^{\circ} \mathrm{C}$ and the slight first weight loss at $368^{\circ} \mathrm{C}$. The sharp peaks might indicate the increase in cellulose content. The partial removal of hemicelluloses in both the cases may be explained by the presence of small peaks in hemicellulose region. The higher decomposition rates of CS-Na, CS-EtIm [Ac]+Na followed by CS-BmIm $[\mathrm{Ac}]+\mathrm{Na}$ could be accounted by the presence of increased cellulosic contents after removal of lignin during respective pretreatments.

In Sugarcane bagasse sample, the degradation of native sample began at $260^{\circ} \mathrm{C}$ and from $285^{\circ} \mathrm{C}$ in the pretreated samples. The untreated sample degraded to $50 \%$ at $388^{\circ} \mathrm{C}$ and improved thermostabilities were shown for all the pretreated samples. The DTG curve of untreated SB showed two very distinct peaks, the first weight loss occurring at $340^{\circ} \mathrm{C}$ in the hemicellulose region and second at $395^{\circ} \mathrm{C}$ in the cellulose region. The prominent peak in the hemicelluloses region indicated the presence of more amount of hemicelluloses than that observed in case of first peak in untreated corn stover sample. Interestingly, SB-Na showed the rapid and maximum decomposition in the cellulose zone due to maximal removal of hemicelluloses. In comparison, SB-EtIm $[\mathrm{Ac}]+\mathrm{Na}$ pretreated material exhibited highest decomposition temperature due to transformation from cellulose I into cellulose II [39]. The same effect was quantitatively proven through maximum release of the sugars. In SB-BmIm $[\mathrm{Ac}]+\mathrm{Na}$, a small shoulder was observed in the hemicellulosic region at $365^{\circ} \mathrm{C}$ followed by the second weight loss peak at $405^{\circ} \mathrm{C}$ in the cellulose region again indicating the degradation of hemicelluloses to a large extent. In SB-EtIm [Ac] and SB-BmIm [Ac], the first weight losses occurred at $370^{\circ} \mathrm{C}$ and $375^{\circ} \mathrm{C}$ respectively and the later peaks occurred at $425^{\circ} \mathrm{C}$ and $415^{\circ} \mathrm{C}$ due to cellulose decomposition. The sharpest decomposition rate peaks in case of SB-Na and CS-Na might be co-related to the pure cellulose content in the samples.

\subsection{Scanning Electron Microscopy}

The scanning electron microscopy was used to study the altered biomass structures after the respective pretreatments on the two agricultural substrates.

Figure 3 shows the impact of combined pretreatments on the surface morphology of corn stover and sugarcane bagasse cell walls. Figure 3(a) shows the compact and fibrillated structure which becomes loosened after the detachment of microfibrils form one another following the sequential pretreatments. The disordered structure increased the surface area and the porosity leading to the increased accessibility of enzymes [42] which is in agreement with the results of 


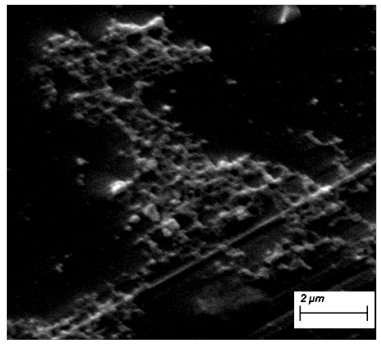

(a)

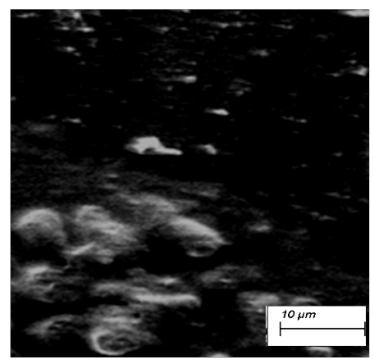

(d)

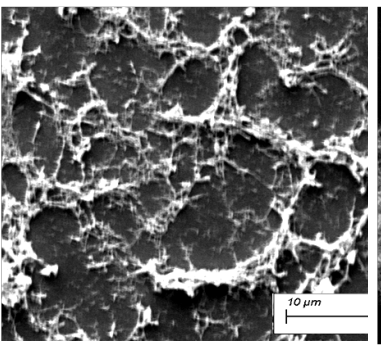

(b)

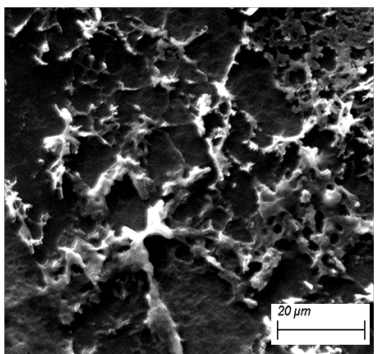

(e)

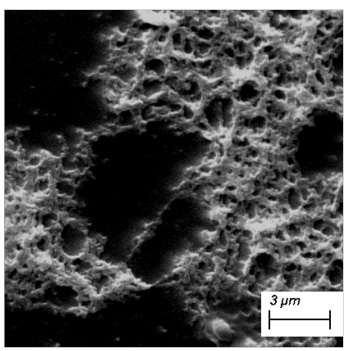

(c)

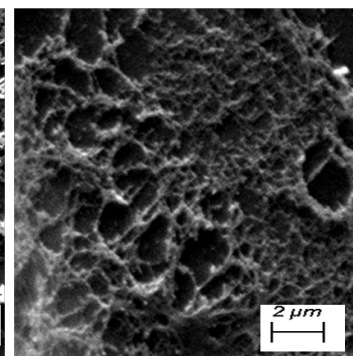

(f)

Figure 3. SEM images of native and pretreated substrates. (a) CS; (b) CS-Etlm [Ac]+Na; (c) $\mathrm{CS}-\mathrm{Bmlm}[\mathrm{Ac}]+\mathrm{Na}$ showing the surface morphologies of the untreated, EtIm $[\mathrm{Ac}]+\mathrm{NaOH}$ treated, $\mathrm{BmIm}[\mathrm{Ac}]+\mathrm{NaOH}$ pretreated corn stover and (d) SB; (e) SB-Etlm $[\mathrm{Ac}]+\mathrm{Na}$; (f) SB-BmIm [Ac]+Na. The untreated, EtIm [Ac] $+\mathrm{NaOH}$ treated, BmIm $[\mathrm{Ac}]+\mathrm{NaOH}$ pretreated sugarcane bagasse.

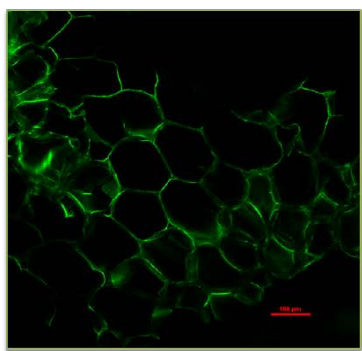

(a)

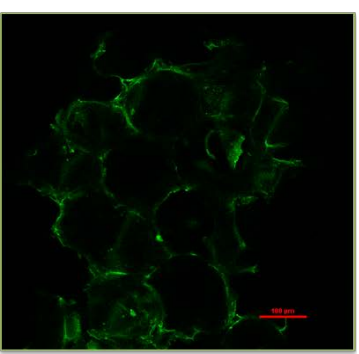

(d)

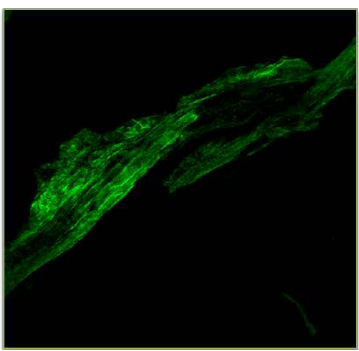

(b)

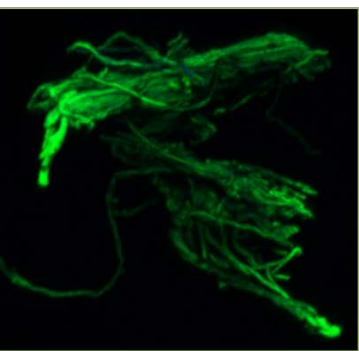

(e)

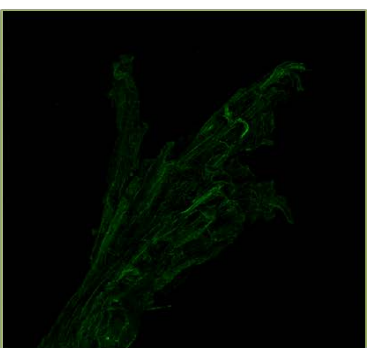

(c)

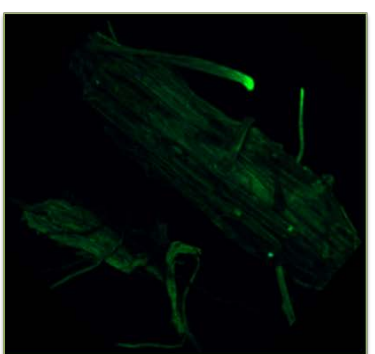

(f)

Figure 4. Confocal fluorescence images of Native and $\mathrm{IL}+\mathrm{NaOH}$ pretreated substrates (a) CS; (b) CS-Etlm [Ac]+Na; (c) CS-Bmlm [Ac]+Na Corn Stover (d) SB; (e) SB-Etlm $[\mathrm{Ac}]+\mathrm{Na}$; (f) SB-BmIm [Ac]+Na. Sugarcane Bagasse. Scale bar is $100 \mu \mathrm{m}$.

enzyme hydrolysis. The much decreased cellulose crystallinity and the lignin removal were the major effects observed after $\mathrm{EmIm}[\mathrm{Ac}]+\mathrm{NaOH}$ pretreatment compared to which the $\mathrm{BmIm}[\mathrm{Ac}]+\mathrm{NaOH}$ treatment showed lesser de-fibrilla- 
tion but maintaining the exposed cell wall surfaces in turn explaining the comparatively lower saccharification rate for the same. The untreated sugarcane bagasse cell wall shows compact cells with a smoother appearance and the pretreatments lead to the distorted and a rougher surface. The collapse of cell walls leading to greater porosity of the cell wall surface is clearly seen in the combined pretreated sample. In one of the previous studies by Elgharbawy et al., empty fruit bunches (EFB) pretreated with Choline acetate [Cho] OAc and choline butyrate $[\mathrm{Cho}] \mathrm{Bu}$ showed very significant differences in their morphology when observed with scanning electron microscopy [43]. Fang et al. showed that the deformed structure and exposed fibres of corn stover after undergoing the thermo-chemical pretreatment using SEM [42]. In our study also, the SEM examined the drastically changed surface textures, increased porosity, swelling of fibres, lignin droplets due to partial delocalization leading to increased digestibility of the substrates.

\subsection{Confocal Scanning Laser Microscopy}

The investigation of lignin distribution in the cell walls of corn stover and sugarcane bagasse was done using intrinsic autofluorescence of lignin as shown in Figure 4. The native CS and SB samples fluoresced due to presence of lignin as could be seen in intact middle lamellae of CS and SB (Figure 4(a), Figure 4(d)) [36]. The lignin distribution was more uniform in case of CS whereas in the SB substrate, it was concentrated more at the cell wall corners. Intact vascular bundles as present in the native samples were nowhere seen in the distorted structures after IL $+\mathrm{NaOH}$ pretreatments. The visualization also revealed that after the sequential $\mathrm{IL}+\mathrm{NaOH}$ pretreatments, the cell wall structures had drastic changes in the morphology as evident from the intertwined, untangled and distorted fibrils due to the regeneration of cellulose. Lignin re-localization could be seen owing to the enhanced autofuorescence lignin signals which seemed to be in accordance with the AFM morphological observations. The signals were more intense in $[\mathrm{EmIm}][\mathrm{OAc}]+\mathrm{NaOH}$ pretreated substrates signaling more lignin re-distribution resulting in increased cellulosic surface area to enzymes which was in line with the enzyme hydrolysis results. The speculation was that the distortion of tissues and structure breakage resulted in increased porosity and enhanced accessibility of the enzymes. According to previous theories, some chemical bonds maintaining the rigidity and compact structure of biomass residues would have dissociated after the pretreatments resulting in the substrates' structural modifications [37]. The modification of the cell wall architecture was clearly visible in case of $\mathrm{IL}+\mathrm{NaOH}$ pretreated substrates being more pronounced in case of SB-EtIm $[\mathrm{Ac}]+\mathrm{Na}$.

\subsection{AFM Analysis}

As seen in the Supplementary file 1: Figure S1(a), Figure S1(b), the native corn stover as well as sugarcane bagasse depicted the rough compact surface 


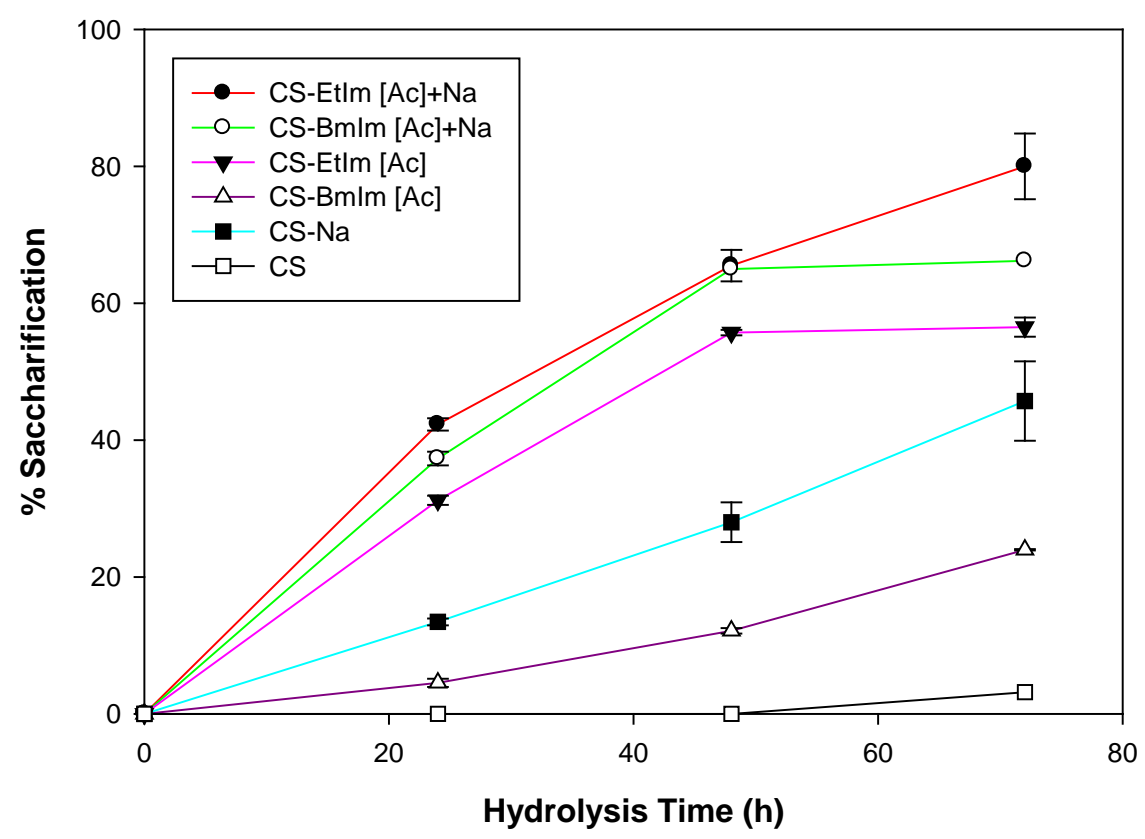

(a)

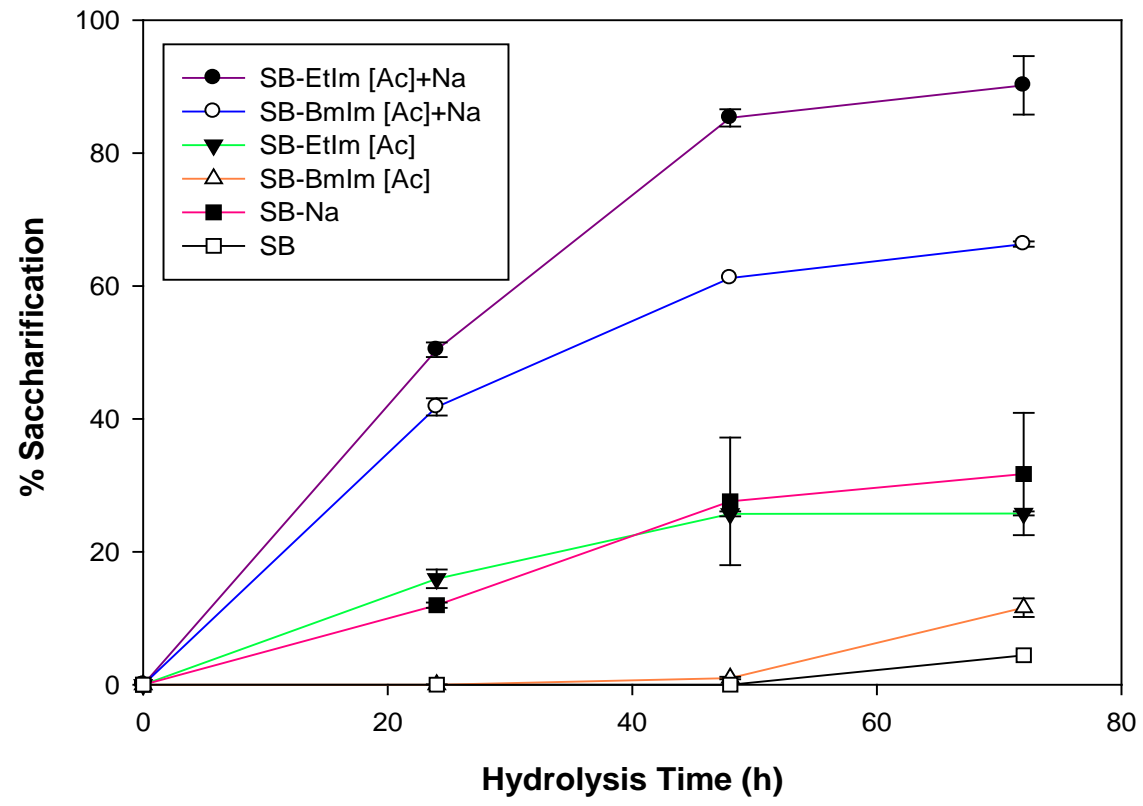

(b)

Figure 5. Enzymatic hydrolysis of (a) corn stover and (b) sugarcane bagasse after IL, $\mathrm{NaOH}$ and $\mathrm{IL}+\mathrm{NaOH}$ pretreatments. The error bars represent the standard deviations taken from the average values of triplicate determinations.

encompassing the network of cellulose bound by hemicelluloses and cross linked lignin. In sequential pretreatment, the cracks appeared to increase the surface area for enhanced enzyme accessibility. It was observed that in CS-BmIm [Ac] and CS-BmIm $[\mathrm{Ac}]+\mathrm{Na}$, lignin re-deposition was the prominent feature and decrease in roughness was also observed due to removal of cross matrix hemicelluloses and lignin polymers. The non-uniform cellulose fibres were observed in 
CS-BmIm $[\mathrm{Ac}]+\mathrm{Na}$. The sequentially pretreated CS-EtIm $[\mathrm{Ac}]+\mathrm{Na}$ showed decreased surface roughness after hemicelluloses disruption as was evident by decreased average roughness Ra value from $5.3 \mathrm{~nm}$ in case of native CS to $5.1 \mathrm{~nm}$ in case (amplitude image) of CS-EtIm $[\mathrm{Ac}]+\mathrm{Na}$. The smoother surface appearance was probably due to lignin re-localization owing to decreased crystallinity. It is hypothesized that the precipitation of lignin granules on the outer surface would expose more of the internal cellulose leading to increased enzymes' accessibility [44]. Similarly, Li et al. [6] showed the decreased roughness of Eucalyptus cell wall after $[\mathrm{Bmim}][\mathrm{OAc}]$ pretreatment. The re-location of lignin in case of [Emim] $[\mathrm{OAc}]+\mathrm{Na}$ pretreated CS could also be co-related with the increased enzymatic saccharification as shown in Figure 4(a). In SB-EtIm [Ac]+Na also, the dominant feature observed was the lignin re-deposition and a very smooth surface owing to maximal removal of hemicelluloses. The cell walls opened up effectively exposing the cellulose fibres for increased enzyme accessibility which was evident in explaining the increased enzymatic saccharification in SB-EtIm $[\mathrm{Ac}]+\mathrm{Na}$ and CS-EtIm [Ac] $+\mathrm{Na}$. Previous studies on corn stover after being pretreated with phosphoric acid strikingly showed the deconstruction of components of the cell wall through AFM [45].

\subsection{Dynamic Light Scattering}

Particle size is an important factor in enzyme digestion and economics of pretreatment as the reduction of size is an energy dependent process [30] [46]. DLS experiments were performed prior to enzymatic hydrolysis experiments to verify the effect of different pretreatments and their respective influences on the particle sizes of the substrates. The particle size reduction increases the accessibility of substrates to enzymes thus enhancing the hydrolysis efficiency [47].

According to previous studies by Peciulyte et al. and Adani et al., the decreased particle size amounts to the enhanced surface area as well as the enzymes' penetration into the fibrous walls resulting in the enzymatic attack on the cellulosic surface [48] [49]. From the present study (Table 1), we could speculate the higher enzymatic efficiencies from the decreased particle sizes in case of CS-BmIm $[\mathrm{Ac}]+\mathrm{Na}$ and SB-EtIm $[\mathrm{Ac}]+\mathrm{Na}$. Whereas, the aberrant increase in particle size in case of CS-EtIm [Ac]+Na and a small increase in case of SB-BmIm $[A c]+N a$ could not be explained well considering the efficient attack of enzyme on both the pretreated substrates leading to increased saccharification. Still after the respective pretreatments, the physical changes are evident i.e. there is a change in size compared to the untreated substrates. One possible reason might be the swelling of fibres in case of the same after the combined pretreatments. It could be inferred from Table 1 that the average particle size of the pretreated samples was reduced except in case of CS-EtIm [Ac]+Na sample. Thus, the pretreated samples with apparent reduction in size lead to the increased digestibility of biomass materials. The results combined with enzyme hydrolysis and CLSM, AFM experiments demonstrated that more of the size re- 
duction and complete cellulose dissolution is not necessary for the increased saccharification rates.

\subsection{Chemical Composition}

The chemical composition results also indicated and supported the other experiments in line that as compared to the native samples, the ionic liquids and alkali pretreated samples could remove a considerable portion of hemicelluloses and lignin with the resultant of making more cellulose available as in content and on the surface to be accessible to enzymes for hydrolysis. It could be observed that the ionic liquids pretreatment helped in the removal of lignin and the alkali pretreatment removed more of hemicellulose. The more solubilization of lignin after pretreatment with ILs could have arisen from the $\pi-\pi$ interactions of respective cations of ionic liquids with the lignin [6] [50]. Also, according to a recent study by Zhang et al., the hydrogen bonding interactions of the lignin with the anions of ILs and $\pi-\pi$ stacking interaction of the lignin with the cations of ILs synergistically affect the dissolution of the lignin in ionic liquids. [51]. The significant reduction was seen in the combined pretreated substrates from $28.2 \%$ of hemicelluloses fraction in native corn stover to $21.1 \%$ and $22.9 \%$ in the CSEtIm $[\mathrm{Ac}]+\mathrm{Na}$ and CS-BmIm $[\mathrm{Ac}]+\mathrm{Na}$ substrates respectively. The same combined pretreatments reduced the hemicellulose and lignin content in the sequentially pretreated substrates to 22.3 and 18.7 in case of SB-EtIm [Ac] $+\mathrm{Na}$ and $21.6 \%$ and $18.9 \%$ in case of SB-BmIm [Ac] $+\mathrm{Na}$ respectively. It could be seen that the BmIm $[\mathrm{Ac}]+\mathrm{Na}$ samples were less effective as compared to the EmIm $[\mathrm{Ac}]+$ Na pretreated ones. A possible explanation for this may be the effective interaction of small sized [Emim] cation with cellulose [52].

\subsection{Enzymatic Hydrolysis}

Enzyme digestibility has a close relation with the effectiveness of applied pretreatments. Hence, the quantitative analysis had to be done in order to substantiate the structural changes. The results were summarised in Figure 5(a), Figure 5(b). Notably, among the two ionic liquids, [EmIm] [OAc] was most effective in dissolution of cellulose and undoubtedly, the combined IL $+\mathrm{NaOH}$ pretreatments gave much better sugar yields than the individual pretreatments. Furthermore, it was observed that both the native samples showed very less percent hydrolysis even after 72 hours owing to the relcacitrance by the crystalline cellulose ensheathed further by complex network of hemicelluloses and lignin. This could be explained by the strong chemical linkage between the hemicelluloses and lignin further surrounding the crystalline cellulosic microfibrils [6]. The hydrolysis rates improved in case of individual ionic liquids and alkali treatments owing to delignification and hemicelluoses removal increasing the further access to cellulose fibres. The combined pretreatments synergistically improved the saccharification yields drastically as compared to the individual treatments. SB and CS pretreated by IL $+\mathrm{NaOH}$ showed $90 \%$ and $80 \%$ saccharification yields 
respectively. There was an increase of $41.59 \%$ and $75.5 \%$ in case of CSEtIm [Ac] $+\mathrm{Na}$ as compared to CSEtIm [Ac] and CS-Na respectively. An incremental increase in case of SBEtIm $[\mathrm{Ac}]+\mathrm{Na}$ was also noticed during the hydrolysis. Both the pretreatments had different effects leading to differences in hydrolysis. The improved hydrolysis in combined pretreatments may be due to the increased amorphous cellulose contents after the disruption of intra molecular and inter molecular hydrogen bonding leading to more of enzyme accessibility stemming from the effective removal of hemicelluloses and lignin [53]. The process economics is yet to be established for the large scale experiments and commercialization thereof. This combination of treatments has unfolded the means of degrading the biomass at milder temperature conditions in case of ionic liquids i.e. $90^{\circ} \mathrm{C}$ as compared to the higher temperatures used and the mild alkali treatments being given for a short time of 3 hours. One of the previous studies used the two step consecutive pretreatments including acid followed by alkaline for sugarcane bagasse substrate. The conversion yield for cellulose was $72 \%$ on the sample treated with $\mathrm{H}_{2} \mathrm{SO}_{4}$ and $1 \% \mathrm{NaOH}$ which was comparatively much better as compared to the $22 \%$ in case of untreated sample [54]. Similarly, Karatzos et al. [55] observed the compositional and structural characteristics of sugarcane bagasse after pretreating it with three of the ionic liquids: 1-ethyl-3-methylimidazolium chloride, 1-butyl-3-methylimidazolium chloride and 1-ethyl-3-methylimidazolium acetate. The concerned study found 1-ethyl-3-methylimidazolium acetate to be the most effective in delignification and also in saccharification yields. Therefore, varied pretreatments have been used to delignify, remove hemicelluloses and to make the cellulose more accessible to enzymatic attack and the microscale changes, thereof, analyzed using sensitive techniques.

\section{Conclusions}

The recalcitrance of lignocellulosic agricultural residual materials such as corn stover, sugarcane bagasse etc. impedes the hydrolysis of the same for the production of sugars. In order to break down the tightly bound matrix of hemicelluloses and lignin surrounding the crystalline cellulose requires the respective substrates' to be pretreated before carrying out the hydrolysis step. Henceforth, investigation of the structural and morphological features of the substrates' is thus, very important to unveil the changes in cellulose, hemicelluloses and lignin following the different pretreatment processes. In the present study, the marvelous ability of ionic liquids in delignification along with the effectiveness of alkaline pretreatment opened the inter-twined compact and crystalline structure (embedded in the matrix of hemicelluloses and lignin) of the pretreated biomasses which was clearly visible by AFM and CSLM. The FTIR analysis was again a very strong conclusive evidence of delignification and removal of hemicelluloses elucidated through the chemical changes. Thermogravimetry showed the increased thermal stability of the pretreated materials and DLS proved the enhanced surface area accessibility through particle size reduction. The syste- 
matic and detailed understanding of the physical and chemical changes in corn stover and sugarcane bagasse following IL dissolution and alkali fractionation have provided a yet another but important platform for overcoming the challenges of biomass deconstruction processes for producing fuels using these alternative sources of energy. The present finding will potentially pave the way for enhanced enzymatic digestions with high biomass loadings of corn stover (CS) and sugarcane bagasse (SB) using commercial and other enzyme tailored cocktails and have implications in the industrial usage of pre-defined synergistic ILs and alkali pretreatments to fractionate and digest the potential agricultural residues.

\section{Acknowledgements}

We duly acknowledge the financial support from Council of Scientific and Industrial Research (CSIR), India (OLP-0105). Authors greatly admire the excellent technical assistance of Mrs. Paramjeet Kaur. Authors are also thankful to Mr. Deepak (CLSM), Mr. Anurag (FTIR), Mr. Shashi (TGA), Mr. Anil (SEM) and Mr. Rishab (AFM) for the expert technical assistance. The manuscript is part of the IMTECH communication number IMT/020/2017.

\section{Authors' Contributions}

IK conducted the experiments, IK and GS analyzed the data and prepared the manuscript. IK drafted the manuscript. Both the authors finalized, read and approved the final manuscript.

\section{Competing Interests}

The authors declare no conflict of interest.

\section{References}

[1] Grillo, G., Banerjee, G., Scott-Craig, J.S. and Walton, J.D. (2010) Improving Enzymes for Biomass Conversion: A Basic Research Perspective. BioEnergy Research, 3, 82-92. https://doi.org/10.1007/s12155-009-9067-5

[2] Zhu, L., O’Dwyer, J.P., Chang, V.S., Granda, C.B. and Holtzapple, M.T. (2008) Structural Features Affecting Biomass Enzymatic Digestibility. Bioresource Technology, 99, 3817-3828. https://doi.org/10.1016/j.biortech.2007.07.033

[3] Taherzadeh, M.J. and Karimi, K. (2008) Pretreatment of Lignocellulosic Wastes to Improve Ethanol and Biogas Production: A Review. International Journal of Molecular Sciences, 9, 1621-1651. https://doi.org/10.3390/ijms9091621

[4] Krishnan, C., Sousa, L.C., Jin, M., Chang, L., Dale, B.E. and Balan, V. (2010) Alkali-Based AFEX Pretreatment for the Conversion of Sugarcane Bagasse and Cane Leaf Residues to Ethanol. Biotechnology and Bioengineering, 107, 441-450. https://doi.org/10.1002/bit.22824

[5] Weerachanchai, P. and Lee, J.M. (2013) Effect of Organic Solvent in Ionic Liquid on Biomass Pretreatment. ACS Sustainable Chemistry and Engineering, 1, 894-902. https://doi.org/10.1021/sc300147f

[6] Li, H.Y., Chen, X., Wang, C.Z., Sun, S.N. and Sun, R.C. (2016) Evaluation of the 
Two-Step Pretreatment with Ionic Liquids and Alkali for Enhancing Enzymatic Hydrolysis of Eucalyptus. Chemical and Anatomical Changes. Biotechnology for Biofuels, 9, 166. https://doi.org/10.1186/s13068-016-0578-y

[7] Sun, N., Rahman, M., Qin, Y., Maxim, M.L., Rodríguez, H. and Rogers, R.D. (2009) Complete Dissolution and Partial Delignification of Wood in the Ionic Liquid 1-ethyl-3-methylimidazolium Acetate. Green Chemistry, 11, 646-655.

https://doi.org/10.1039/b822702k

[8] Brandt, A., Hallett, J.P., Leak, D.J., Murphy, R.J. and Welton, T. (2010) The Effect of the Ionic Liquid Anion in the Pretreatment of Pine Wood Chips. Green Chemistry, 12, 672-679. https://doi.org/10.1039/b918787a

[9] Carrillo, F., Lis, M.J., Colom, X., López-Mesasa, M. and Valldeperas, J. (2005) Effect of Alkali Pretreatment on Cellulase Hydrolysis of Wheat Straw: Kinetic Study. Process Biochemistry, 40, 3360-3364. https://doi.org/10.1016/j.procbio.2005.03.003

[10] Silverstein, R.A., Chen, Y., Sharma-Shivappa, R.R., Boyette, M.D. and Osborne, J. (2007) A Comparison of Chemical Pretreatment Methods for Improving Saccharification of Cotton Stalks. Bioresource Technology, 98, 3000-3011.

https://doi.org/10.1016/j.biortech.2006.10.022

[11] Rodríguez-Vázquez, R., Villanueva-Ventura, G. and Rios-Leal, E. (1992) Sugarcane Bagasse Pith Dry Pretreatment for Single Cell Protein Production. Bioresource Technology, 39, 17-22. https://doi.org/10.1016/0960-8524(92)90051-X

[12] Hsu, T.A. (1996) Pretreatment of Biomass. In: Wyman, C.E., Ed., Handbook on Bioethanol, Production and Utilization: Pretreatment of Biomass, Taylor and Francis, Washington DC, 179-212.

[13] Chandel, A.K., Antunes, F.A.F., Anjos, V., Bell, M.J.V., Rodrigues, L.N., Singh, O.V., Rosa, C.A., Pagnocca, F.C. and da Silva, S.S. (2013) Ultra-Structural Mapping of Sugarcane Bagasse after Oxalic Acid Fiber Expansion (OAFEX) and Ethanol Production by Candida shehatae and Saccharomyces cerevisiae. Biotechnology for Biofuels, 6, 4. https://doi.org/10.1186/1754-6834-6-4

[14] Goldemberg, J. (2008) The Brazilian Biofuels Industry. Biotechnology for Biofuels, 1, 6. https://doi.org/10.1186/1754-6834-1-6

[15] Kurian, J.K., Nair, G.R., Hussain, A. and Vijaya Raghavan, G.S. (2013) Feedstocks, Logistics and Pre-Treatment Processes for Sustainable Lignocellulosic Biorefineries: A Comprehensive Review. Renewable and Sustainable Energy Reviews, 25, 205-219. https://doi.org/10.1016/j.rser.2013.04.019

[16] Somerville, C., Bauer, S., Brininstool, G., Facette, M., Hamann, T., Milne, J., Osborne, E., Paredez, A., Persson, S., Raab, T., Vorwerk, S. and Young, H. (2004) Toward a Systems Approach to Understanding Plant Cell Walls. Science, 306, 22062211. https://doi.org/10.1126/science.1102765

[17] Ayeni, O.A., Adeeyo, O.A., Oresegun, O.M. and Oladimeji, T.E. (2015) Compositional Analysis of Lignocellulosic Materials: Evaluation of an Economically Viable Method Suitable for Woody and Non-Woody Biomass. American Journal of Engineering Research, 4, 14-19.

[18] Li, S., Xu, S., Liu, S., Yang, C. and Lu, Q. (2004) Fast Pyrolysis of Biomass in Free-Fall Reactor for Hydrogen-Rich Gas. Fuel Processing Technology, 85, 1201-1211. https://doi.org/10.1016/j.fuproc.2003.11.043

[19] Miller, G.L. (1959) Use of Dinitrosalicyclic Acid Reagent for Determination of Reducing Sugar. Analytical Chemistry, 31, 426-428.

https://doi.org/10.1021/ac60147a030

[20] Kristensen, J.B., Thygesen, L.G., Felby, C., Jørgensen, H. and Elder, T. (2008) 
Cell-Wall Structural Changes in Wheat Straw Pretreated for Bioethanol Production. Biotechnology for Biofuels, 1, 1-9. https://doi.org/10.1186/1754-6834-1-5

[21] Lynam, J. and Coronella, C. (2015) Loblolly Pine Pretreatment by Ionic LiquidGlycerol Mixtures. Biomass Conversion and Biorefinery, 6, 247-260.

[22] Lynam, J.G., Chow, G.I., Hyland, P.L. and Coronella, C.J. (2016) Corn Stover Pretreatment by Ionic Liquid and Glycerol Mixtures with Their Density, Viscosity, and Thermogravimetric Properties. ACS Sustainable Chemistry and Engineering, 4, 3786-3793. https://doi.org/10.1021/acssuschemeng.6b00480

[23] Nelson, M.L. and O'Connor, R.T. (1964) Relation of Certain Infrared Bands to Cellulose Crystallinity and Crystal Lattice Type. Part II. A New Infrared Ratio for Estimation of Crystallinity in Celluloses I and II. Journal of Applied Polymer Science, 8 , 1325-1341.

[24] Oh, S.Y., Yoo, D.I., Shin, Y., Kim, H.C., Kim, H.Y., Chung, Y.S., Park, W.H. and Youk, J.H. (2005) Crystalline Structure Analysis of Cellulose Treated with Sodium Hydroxide and Carbon Dioxide by Means of X-Ray Diffraction and FTIR Spectroscopy. Carbohydrate Research, 340, 2376-2391.

https://doi.org/10.1016/j.carres.2005.08.007

[25] Colom, X., Carrillo, F., Nogués, F. and Garriga, P. (2003) Structural Analysis of Photodegraded Wood by Means of FTIR Spectroscopy. Polymer Degradation and Stability, 80, 543-549. https://doi.org/10.1016/S0141-3910(03)00051-X

[26] Chandel, A.K., Antunes, F.A.F., Anjos, V., Bell, M.J.V., Rodrigues, L.N., Polikarpov, I., Azevedo, ER de., Bernardinelli, O.D., Rosa, C.A., Pagnocca, F.C. and da Silva, S.S. (2014) Multi-Scale Structural and Chemical Analysis of Sugarcane Bagasse in the Process of Sequential Acid-Base Pretreatment and Ethanol Production by Scheffersomyces shehatae and Saccharomyces cerevisiae. Biotechnology for Biofuels, 7, 63. https://doi.org/10.1186/1754-6834-7-63

[27] Liu, C.G., Qin, J.C., Liu, L.Y., Jin, B.W. and Bai, F.W. (2016) Combination of Ionic Liquid and Instant Catapult Steam Explosion Pretreatments for Enhanced Enzymatic Digestibility of Rice Straw. ACS Sustainable Chemistry and Engineering, 4, 577-582. https://doi.org/10.1021/acssuschemeng.5b00990

[28] Sun, R.C. and Tomkinson, J. (2002) Characterization of Hemicelluloses Obtained by Classical and Ultrasonically Assisted Extractions from Wheat Straw. Carbohydrate Polymers, 50, 263-271. https://doi.org/10.1016/S0144-8617(02)00037-1

[29] Hsu, T.C., Guo, G.L., Chen, W.H. and Hwang, W.S. (2010) Effect of Dilute Acid Pretreatment of Rice Straw on Structural Properties and Enzymatic Hydrolysis. Bioresource Technology, 101, 4907-4913. https://doi.org/10.1016/j.biortech.2009.10.009

[30] Hou, X.-D., Li, N. and Z, M.-H. (2013) Facile and Simple Pretreatment of Sugar Cane Bagasse without Size Reduction Using Renewable Ionic Liquids-Water Mixtures. ACS Sustainable Chemistry and Engineering, 1, 519-526. https://doi.org/10.1021/sc300172v

[31] Boeriu, C.G., Bravo, D., Gosselink, R.J. and van Dam, J.E. (2004) Characterisation of Structure-Dependent Functional Properties of Lignin with Infrared Spectroscopy. Industrial Crops and Products, 20, 205-218. https://doi.org/10.1016/j.indcrop.2004.04.022

[32] Li, C., Knierim, B., Manisseri, C., Arora, R., Scheller, H.V., Auer, M., Vogel, K.P., Simmons, B.A. and Singh, S. (2010) Comparison of Dilute Acid and Ionic Liquid Pretreatment of Switchgrass: Biomass Recalcitrance, Delignification and Enzymatic Saccharification. Bioresource Technology, 101, 4900-4906. 
https://doi.org/10.1016/j.biortech.2009.10.066

[33] Yang, S., Zhang, Y., Yue, W., Wang, W., Wang, Y.Y., Yuan, T.Q. and Sun, R.C. (2016) Valorization of Lignin and Cellulose in Acid-Steam-Exploded Corn Stover by a Moderate Alkaline Ethanol Post-Treatment Based on an Integrated Biorefinery Concept. Biotechnology for Biofuels, 9, 238. https://doi.org/10.1186/s13068-016-0656-1

[34] Corrales, R.C.N.R., Mendes, F.M.T., Perrone, C.C., Sant'Anna, C., de Souza, W., Abud, Y., da Silva Bon, E.P. and Ferreira-Leitão, V. (2012) Structural Evaluation of Sugar Cane Bagasse Steam Pretreated in the Presence of $\mathrm{CO}_{2}$ and $\mathrm{SO}_{2}$. Biotechnology for Biofuels, 5, 36. https://doi.org/10.1186/1754-6834-5-36

[35] Raveendran, K., Ganesh, A. and Khilar, K.C. (1996) Pyrolysis Characteristics of Biomass and Biomass Components. Fuel, 75, 987-998.

https://doi.org/10.1016/0016-2361(96)00030-0

[36] Sun, F.F., Zhao, X., Hong, J., Tang, Y., Wang, L., Sun, H., Li, X. and Hu, J. (2016) Industrially Relevant Hydrolyzability and Fermentability of Sugarcane Bagasse Improved Effectively by Glycerol Organosolv Pretreatment. Biotechnology for Biofuels, 9, 59. https://doi.org/10.1186/s13068-016-0472-7

[37] Sun, F.F., Wang, L., Hong, J., Ren, J., Du, F., Hu, J., Zhang, Z. and Zhou, B. (2015) The Impact of Glycerol Organosolv Pretreatment on the Chemistry and Enzymatic Hydrolyzability of Wheat Straw. Bioresource Technology, 187, 354-361. https://doi.org/10.1016/j.biortech.2015.03.051

[38] King, A.W.T., Parviainen, A., Karhunen, P., Matikainen, J., Hauru, L.K.J., Sixtab, H. and Kilpelainen, I. (2012) Relative and Inherent Reactivities of Imidazolium-Based Ionic Liquids: The Implications for Lignocellulose Processing Applications. RSC Advances, 2, 8020-8026. https://doi.org/10.1039/c2ra21287k

[39] Zhang, J., Feng, L., Wang, D., Zhang, R., Liu, G. and Cheng, G. (2014) Thermogravimetric Analysis of Lignocellulosic Biomass with Ionic Liquid Pretreatment. Bioresource Technology, 153, 379-382. https://doi.org/10.1016/j.biortech.2013.12.004

[40] Singh, S., Cheng, G., Sathitsuksanoh, N., Wu, D., Varanasi, P., George, A., Balan, V., Gao, X., Kumar, R., Dale, B.E., Wyman, C.E. and Simmons, B.A. (2015) Comparison of Different Biomass Pretreatment Techniques and Their Impact on Chemistry and Structure. Frontiers in Energy Research, 2, 62.

https://doi.org/10.3389/fenrg.2014.00062

[41] Yang, H., Yan, R., Chen, H., Lee, D.H. and Zheng, C.G. (2007) Characteristics of Hemicellulose, Cellulose, and Lignin Pyrolysis. Fuel, 86, 1781-1788. https://doi.org/10.1016/j.fuel.2006.12.013

[42] Fang, W., Weisheng, N., Andong, Z. and Weiming, Y. (2015) Enhanced Anaerobic Digestion of Corn Stover by Thermo-Chemical Pretreatment. International Journal of Agricultural \& Biological Engineering, 8, 84-90.

[43] Elgharbawy, A.A., Alam, M.Z., Kabbashi, N.A., Moniruzzaman, M. and Jamal, P. (2016) Evaluation of Several Ionic Liquids for in Situ Hydrolysis of Empty Fruit Bunches by Locally-Produced Cellulose. 3 Biotech, 6, 128.

[44] Chundawat, S.P.S., Donohoe, B.S., Sousa, L.D., Elder, T., Agarwal, U.P., Lu, F.C., Ralph, J., Himmel, M.E., Balan, V. and Dale, B.E. (2011) Multi-Scale Visualization and Characterization of Lignocellulosic Plant Cell Wall Deconstruction during Thermochemical Pretreatment. Energy and Environmental Science, 4, 973-984. https://doi.org/10.1039/c0ee00574f

[45] Zhang, Y.P., Ding, S., Mielenz, J.R., Cui, J., Elander, R.T., Laser, M., Himmel, M.E., McMillan, J.R. and Lynd, L.R. (2007) Fractionating Recalcitrant Lignocellulose at 
Modest Reaction Conditions. Biotechnology and Bioengineering, 97, 214-223. https://doi.org/10.1002/bit.21386

[46] Vidal, B.C., Dien, B.S., Ting, K. and Singh, V. (2011) Influence of Feedstock Particle Size on Lignocelluloses Conversion: A Review. Applied Biochemistry and Biotechnology, 164, 1405-1421. https://doi.org/10.1007/s12010-011-9221-3

[47] Kadić, A., Palmqvist, B. and Lidén, G. (2014) Effects of Agitation on Particle-Size Distribution and Enzymatic Hydrolysis of Pretreated Spruce and Giant Reed. Biotechnology for Biofuels 7, 77. https://doi.org/10.1186/1754-6834-7-77

[48] Peciulyte, A., Karlstrom, K., Larsson, P.T. and Olsson, L. (2015) Impact of the Supramolecular Structure of Cellulose on the Efficiency of Enzymatic Hydrolysis. Biotechnology for Biofuels, 8, 56.

[49] Adani, F., Papa, G., Schievano, A., Cardinale, G., D’Imporzano, G. and Tambone, F. (2011) Nanoscale Structure of the Cell Wall Protecting Cellulose from Enzyme Attack. Environmental Science and Technology, 45, 1107-1113. https://doi.org/10.1021/es1020263

[50] Shill, K., Padmanabhan, S., Xin, Q., Prausnitz, J.M., Clark, D.S. and Blanch, H.W. (2011) Ionic Liquid Pretreatment of Cellulosic Biomass: Enzymatic Hydrolysis and Ionic Liquid Recycle. Biotechnology and Bioengineering, 108, 511-520. https://doi.org/10.1002/bit.23014

[51] Zhang, Y., He, H., Dong, K., Fanc, M. and Zhang, S. (2017) DFT Study on Lignin Dissolution in Imidazolium Based Ionic Liquids. RSC Advances, 7, 12670-12681. https://doi.org/10.1039/C6RA27059J

[52] Nguyen, T.A.D., Kim, K.R., Han, S.J., Cho, H.Y., Kim, J.W., Park, S.M., Park, J.C. and Sim, S.J. (2010) Pretreatment of Rice Straw with Ammonia and Ionic Liquid for Lignocelluloses Conversion to Fermentable Sugars. Bioresource Technology, 101, 7432-7438. https://doi.org/10.1016/j.biortech.2010.04.053

[53] Geng, X. and Henderson, W.A. (2012) Pretreatment of Corn Stover by Combining Ionic Liquid Dissolution with Alkali Extraction. Biotechnology and Bioengineering, 109, 84-91. https://doi.org/10.1002/bit.23281

[54] Rezende, C.A., de Lima, M.A., Maziero, P., deAzevedo, E.R., Garcia, W. and Polikarpov, I. (2011) Chemical and Morphological Characterization of Sugarcane Bagasse Submitted to a Delignification Process for Enhanced Enzymatic Digestibility. Biotechnology for Biofuels, 4, 54. https://doi.org/10.1186/1754-6834-4-54

[55] Karatzos, S.M., Edye, L.A. and Doherty, W.O.S. (2012) Sugarcane Bagasse Pretreatment using Three Imidazolium-Based Ionic Liquids; Mass Balances and Enzyme Kinetics. Biotechnology for Biofuels, 5, 62.

https://doi.org/10.1186/1754-6834-5-62 


\section{Supplementary Material}

Supplementary Material File 1. Supplementary Figures and Tables.

Table S1. Functional assignment of the absorbance bands.

\begin{tabular}{|c|c|c|}
\hline Wavenumber $\left(\mathrm{cm}^{-1}\right)$ & Assigned functional group & References \\
\hline 897 & Glycosidic Linkage & Liu et al., 2016 \\
\hline 1259 & $\begin{array}{c}\text { C-O stretching in lignin and } \\
\text { hemicellulose }\end{array}$ & Li et al., 2016 \\
\hline 1373 & $\begin{array}{l}\mathrm{C}-\mathrm{H} \text { deformation in cellulose and } \\
\text { hemicellulose }\end{array}$ & Li et al., 2016; Li et al., 2010 \\
\hline 1427 & $-\mathrm{CH} 2$ scissoring motion & Li et al., 2016 \\
\hline 1450 & Lignin aromatic skeletal vibration & Yang et al., 2016 \\
\hline 1505 & Lignin aromatic skeletal vibration & $\begin{array}{l}\text { Lynam et al., 2016; Li et al., } \\
\text { 2016; }\end{array}$ \\
\hline 1595 & $\begin{array}{l}\text { Lignin aromatic ring vibration+ } \\
\text { C-H deformation }\end{array}$ & Yang et al., 2016 \\
\hline 1638 & $\mathrm{C}=\mathrm{C}$ aromatic skeletal vibration & - \\
\hline 1732 & $\begin{array}{c}\mathrm{C}=\mathrm{O} \text { unconjugated stretching of } \\
\text { the hemicellulose acetyl }\end{array}$ & Li et al., 2016 \\
\hline $2850 ; 2918$ & $\begin{array}{l}\mathrm{CH} 2 \text { symmetric stretching; } \mathrm{CH} \\
\text { asymmetric stretching }\end{array}$ & Colom et al., 2003 \\
\hline
\end{tabular}

Table S2. Chemical composition of native and pretreated Corn stover (CS) and sugarcane bagasse (SB).

\begin{tabular}{|c|c|c|c|}
\hline & Cellulose (\%) & Hemicellulose (\%) & Lignin (\%) \\
\hline CS & $43.4 \pm 0.42$ & $28.20 \pm 0.10$ & $20.4 \pm 0.35$ \\
\hline $\mathrm{CS}-\mathrm{Na}$ & $45.7 \pm 0.2$ & $23.1 \pm 0.4$ & $19.6 \pm 0.1$ \\
\hline CS-EtIm [Ac] & $44.3 \pm 0.4$ & $27.6 \pm 0.2$ & $18.2 \pm 0.4$ \\
\hline CS-BmIm [Ac] & $43.9 \pm 0.3$ & $28.7 \pm 0.4$ & $19.4 \pm 0.2$ \\
\hline $\mathrm{CS}-\mathrm{EtIm}[\mathrm{Ac}]+\mathrm{Na}$ & $53.0 \pm 0.1$ & $21.1 \pm 0.2$ & $17.0 \pm 0.4$ \\
\hline $\mathrm{CS}-\mathrm{BmIm}[\mathrm{Ac}]+\mathrm{Na}$ & $52.1 \pm 0.1$ & $22.9 \pm 0.3$ & $18.1 \pm 0.4$ \\
\hline SB & $42.5 \pm 0.3$ & $20.3 \pm 0.1$ & $21.2 \pm 0.2$ \\
\hline $\mathrm{SB}-\mathrm{Na}$ & $43.2 \pm 0.3$ & $19.1 \pm 0.1$ & $20.2 \pm 0.2$ \\
\hline SB-EtIm [Ac] & $43.6 \pm 0.2$ & $21 \pm 0.1$ & $20.7 \pm 0.1$ \\
\hline SB-BmIm [Ac] & $42.9 \pm 0.1$ & $21.6 \pm 0.4$ & $21.5 \pm 0.0$ \\
\hline $\mathrm{SB}-\mathrm{EtIm}[\mathrm{Ac}]+\mathrm{Na}$ & $53.9 \pm 0.1$ & $22.3 \pm 0.2$ & $18.7 \pm 0.2$ \\
\hline $\mathrm{SB}-\mathrm{BmIm}[\mathrm{Ac}]+\mathrm{Na}$ & $51.7 \pm 0.2$ & $21.6 \pm 0.1$ & $18.9 \pm 0.1$ \\
\hline
\end{tabular}

The $\%$ composition readings are expressed as an average $( \pm \mathrm{SD})$ of duplicate experiment determinations. 


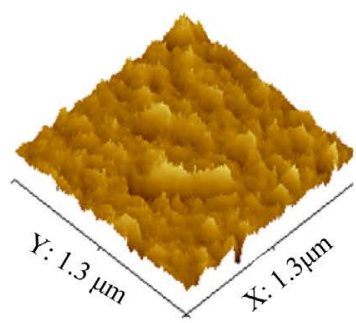

(A) Untreated CS

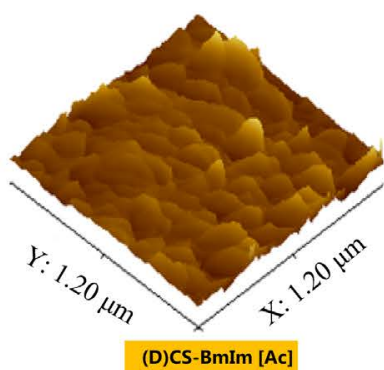

(D)CS-BmIm [AC]

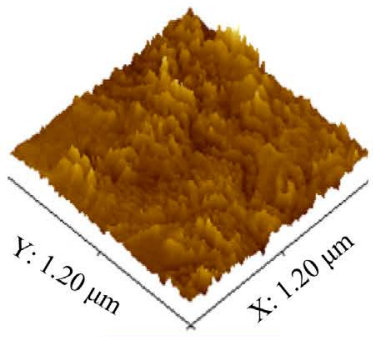

(A) Untreated SB

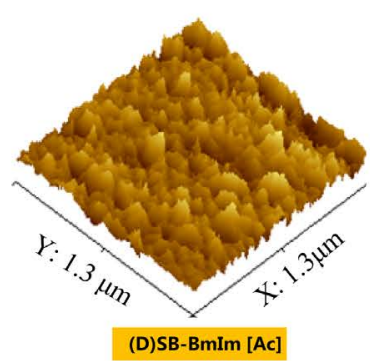

(D)SB-BmIm [Ac]

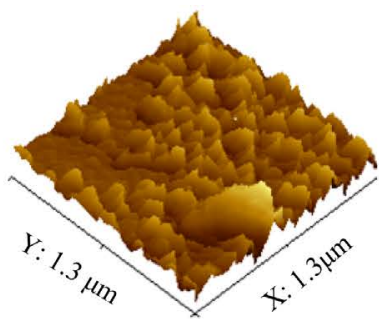

(B) CS-Na

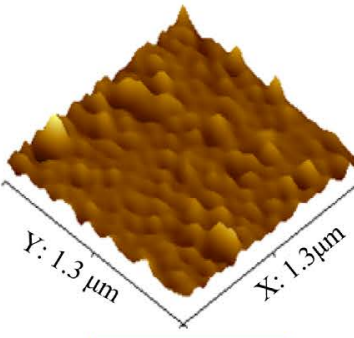

(E)CS-Etim [Ac] $+\mathrm{Na}$

(a)

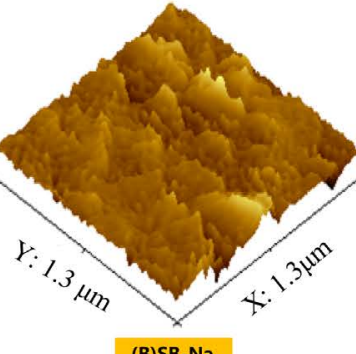

(B)SB-Na

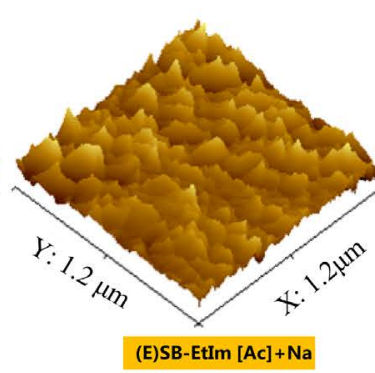

(b)

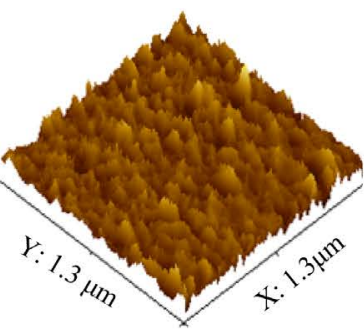

(C)CS-EtIm [Ac]

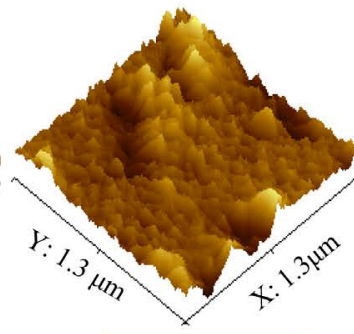

(F)CS-BmIm[Ac] $+\mathrm{Na}$

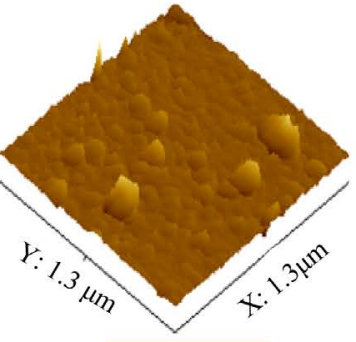

(C)SB-EtIm [Ac]

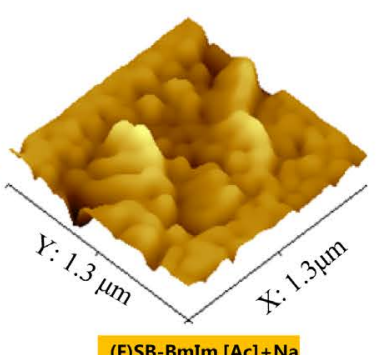

(F)SB-BmIm $[\mathrm{Ac}]+\mathrm{Na}$

Figure S1. (a) AFM images of Native, IL, $\mathrm{NaOH}$ and IL $+\mathrm{NaOH}$ pretreated corn stover; (b) AFM images of Native, IL, $\mathrm{NaOH}$ and IL $+\mathrm{NaOH}$ pretreated sugarcane bagasse. 